\title{
Reference ranges for flow velocities and the indices of the ductus venosus in low-risk pregnancies
}

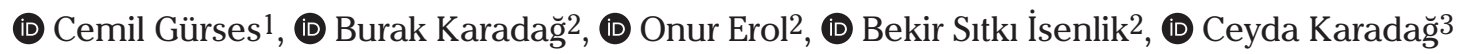 \\ ${ }^{1}$ Clinic of Radiology, University of Health Sciences Turkey, Antalya Training and Research Hospital, Antalya, Turkey \\ ${ }^{2}$ Clinic of Obstetrics and Gynecology, University of Health Sciences Turkey, Antalya Training and Research Hospital, \\ Antalya, Turkey \\ 3Department of Obstetrics and Gynecology, Akdeniz University Faculty of Medicine, Antalya, Turkey
}

\section{Abstract}

Objective: Ductus venosus blood flow velocity measurements are mandatory in many clinical indications. The evaluation of the flow is performed either by comparing results with general reference tables or by qualitative assessment of the "a" flow, in regard to reversed or absent flow in the spectral waveforms. The aim was to develop normal reference ranges in low-risk pregnancies in our population.

Material and Methods: Measurements of flow velocities (S, v, D, a) and indices (pulsatility index for veins, peak velocity index for veins, a/S, S/a) were performed by a single experienced specialist in 1279 singleton, uncomplicated pregnancies between 11 and 40 weeks gestation. The absolute flow velocities (S, v, D, a, VmPeak) and indices were obtained from spectral waveforms using the equipment producer's inbuilt system. The still images were stored in the picture archiving and communication system.

Results: The predicted reference ranges of the ductus venosus blood flow velocities according to the gestational age are shown in tables and graphics. Predicted reference curves based on the $5^{\text {th }}$ and $95^{\text {th }}$ percentiles according to gestational week were plotted and are given in tables and figures.

Conclusion: Normal reference ranges for absolute flow velocities and indices were calculated from a population of uncomplicated pregnancies attending a tertiary care center. The measurements were made from both the classic patterns of the waveforms and also considered variants of the spectral waveforms, which have recently been reported, for the first time in the medical literature. (J Turk Ger Gynecol Assoc 2021; 22: 300-11)

Keywords: Doppler, ductus venosus, ultrasonography

Received: 14 December, 2020 Accepted: 26 May, 2021

\section{Introduction}

Ductus venosus (DV) Doppler assessments play a critical role, not only for the diagnosis of chromosomal abnormalities and congenital cardiac defects in early pregnancy, but also for determining cardiovascular health in the follow up of the pregnancy. In the UK DV Doppler assessment has been suggested for use in surveillance and timing of delivery (1).

The DV spectral waveform pattern has two peaks (S \& D) and two nadirs ( $\mathrm{v} \& \mathrm{a}$ ) in a cardiac cycle. The "S" and "D" peaks correspond to the maximum and "v" and "a" nadirs correspond to the minimum intra-atrial pressure, which accelerates or decelerates the forward flow in DV throughout a cardiac cycle
(Figure 1-7, Video 1-3). The flow in DV is assessed by either qualitatively observing the spectral pulsed Doppler (PD) flow and checking the "a" nadir in the waveform to assess if it is "reversed" or "not", and or quantitatively comparing the measurements with published reference ranges for each gestational week of pregnancy (2-5).

Even though there are already published reference values, advancing technologies to visualize the DV and obtaining reproducible measurements are now easier. Therefore reassessment and publication of reference limits is warranted. The aim of this study was to derive reference ranges of sonography angle-dependent absolute flow velocities for $\mathrm{S}, \mathrm{v}$, $\mathrm{D}$, a and VmPeak and angle-independent Doppler indices of 
pulsatility index for veins (PIV), peak velocity index for veins (PVIV), a/S, S/a, preload index [(S - a)/S)] $(6,7)$ and SIA index $[\mathrm{S} /(\mathrm{v}+\mathrm{a})](8)$ (Figure 1).

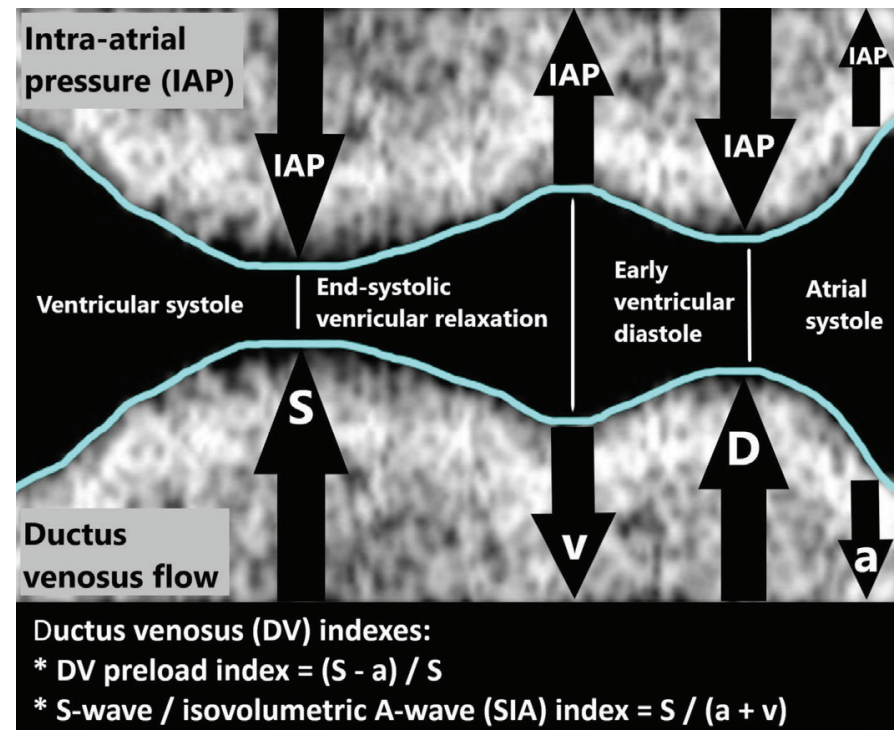

Figure 1. Relationships between the DV flow velocities and the intra-atrial pressure changes in a cardiac cycle. DV flow velocity increased while intra-atrial pressure decreased and vice versa

S: Velocity in ventricular contraction, $v$ : Velocity in end-systolic ventricular relaxation, $D$ : Velocity in early ventricular diastole, a: Velocity in atrial systole

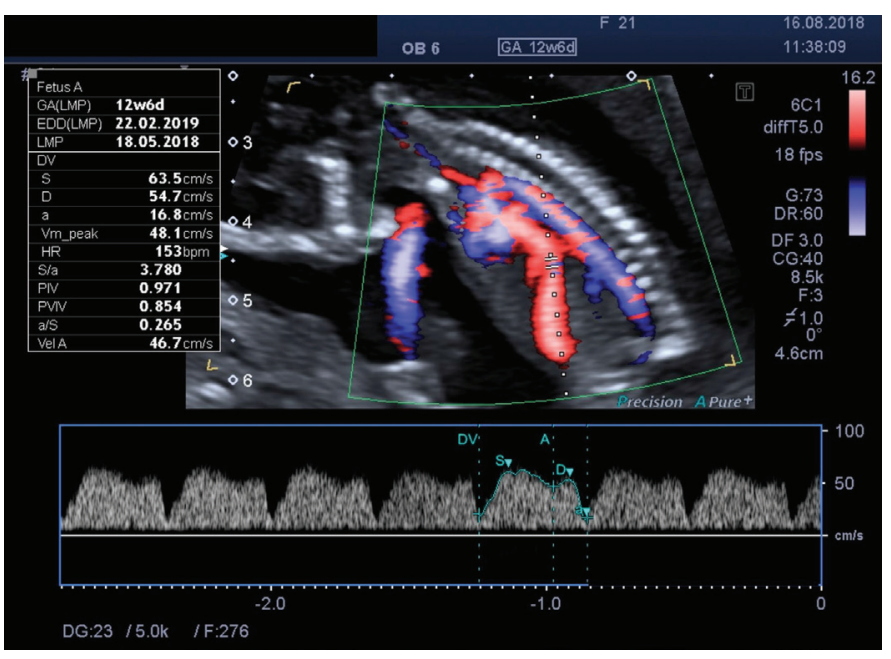

Figure 2. The measurement of ductus venosus flow velocity and indices 12 weeks' gestation

DR: Dynamic range, DF: Dynamic frequency, CG: Color gain, F: filter, DV: Ductus venosus, S: Velocity in ventricular contraction, D: Velocity in early ventricular diastole, a: Velocity in atrial systole, VmPeak: Time-averaged maximum velocity, S/a: The ratio of velocity in ventricular systole to velocity in atrial contraction, PIV: Pulsatility index for vein, PVIV: Peak velocity index for vein, a/S: The ratio of velocity in atrial contraction to velocity in ventricular systole

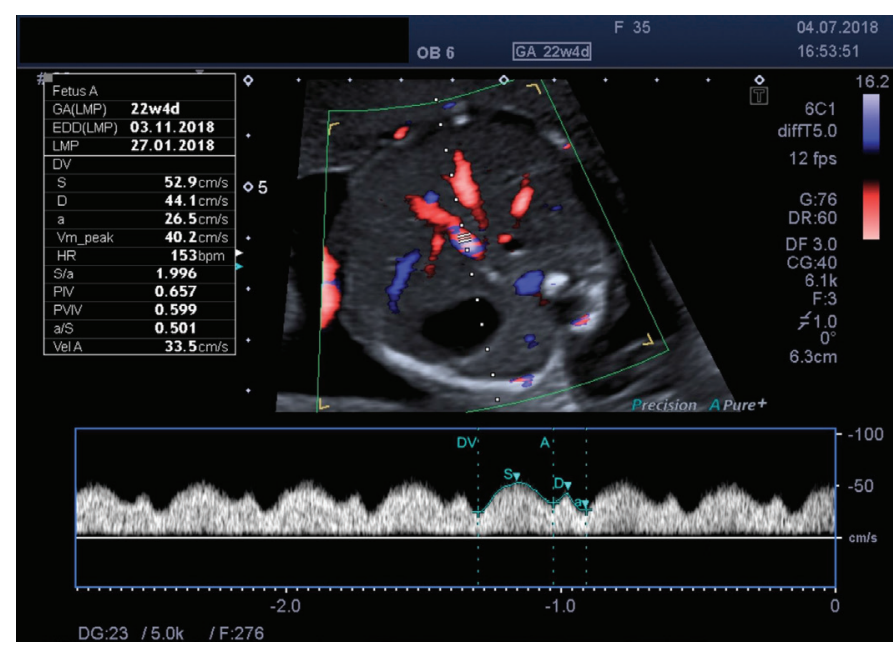

Figure 3. The measurement of ductus venosus flow velocity and indices 22 weeks' gestation in the oblique transverse plane

DR: Dynamic range, DF: Dynamic frequency, CG: Color gain, $F$ : filter, DV: Ductus venosus, S: Velocity in ventricular contraction, D: Velocity in early ventricular diastole, a: Velocity in atrial systole, VmPeak: Time-averaged maximum velocity, S/a: The ratio of velocity in ventricular systole to velocity in atrial contraction, PIV: Pulsatility index for vein, PVIV: Peak velocity index for vein, $a / S$ : The ratio of velocity in atrial contraction to velocity in ventricular systole

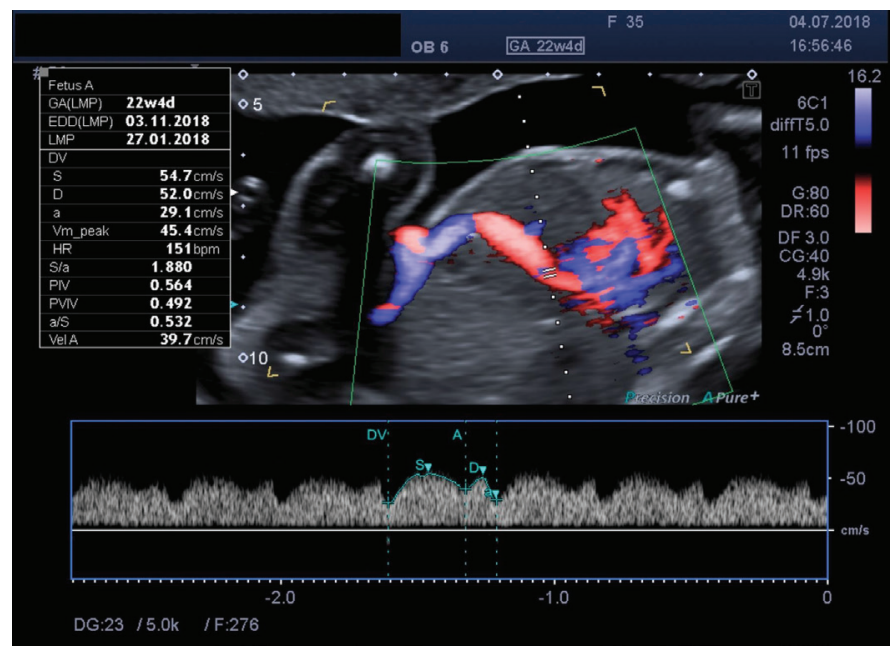

Figure 4. The measurement of ductus venosus flow velocity and indices 22 weeks' gestation of the same patients in figure 3 in the sagittal plane

DR: Dynamic range, DF: Dynamic frequency, $C G$ : Color gain, $F$ : filter, DV: Ductus venosus, $S$ : Velocity in ventricular contraction, D: Velocity in early ventricular diastole, a: Velocity in atrial systole, VmPeak: Time-averaged maximum velocity, S/a: The ratio of velocity in ventricular systole to velocity in atrial contraction, PIV: Pulsatility index for vein, PVIV: Peak velocity index for vein, a/S: The ratio of velocity in atrial contraction to velocity in ventricular systole 


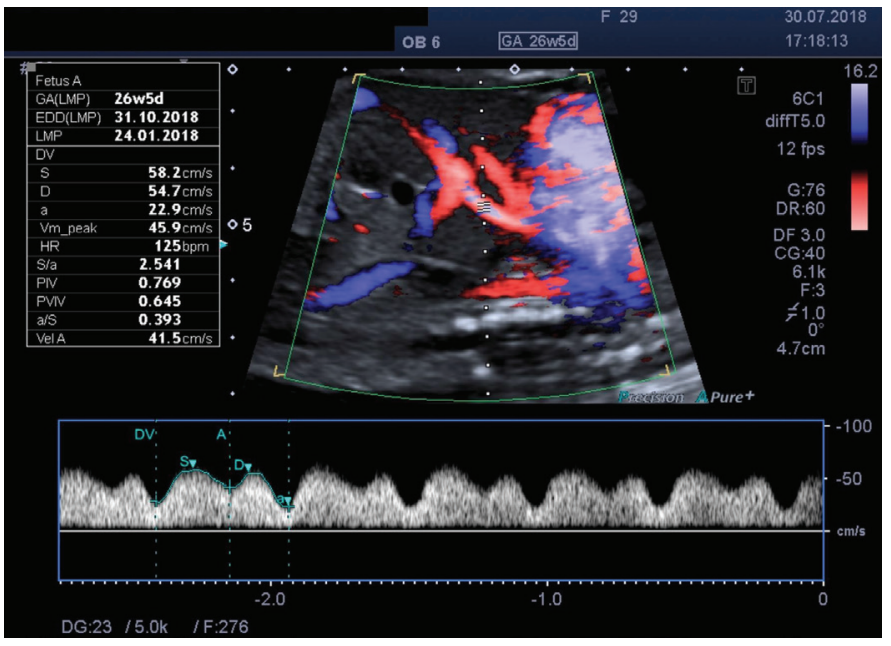

Figure 5. The measurement of ductus venosus flow velocity and indices 26 weeks' gestation

DR: Dynamic range, DF: Dynamic frequency, $C G$ : Color gain, $F$ : filter, DV: Ductus venosus, S: Velocity in ventricular contraction, D: Velocity in early ventricular diastole, a: Velocity in atrial systole, VmPeak: Time-averaged maximum velocity, S/a: The ratio of velocity in ventricular systole to velocity in atrial contraction, PIV: Pulsatility index for vein, PVIV: Peak velocity index for vein, a/S: The ratio of velocity in atrial contraction to velocity in ventricular systole

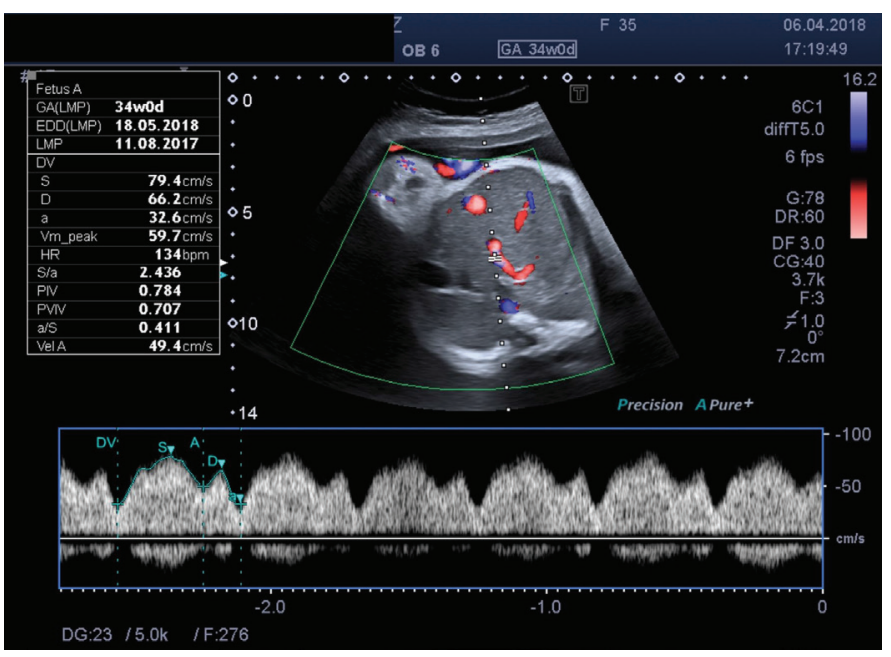

Figure 6. The measurement of ductus venosus flow velocity and indices 34 weeks' gestation in the oblique transverse plane

DR: Dynamic range, DF: Dynamic frequency, CG: Color gain, $F$ : filter, DV: Ductus venosus, S: Velocity in ventricular contraction, D: Velocity in early ventricular diastole, a: Velocity in atrial systole, VmPeak: Time-averaged maximum velocity, S/a: The ratio of velocity in ventricular systole to velocity in atrial contraction, PIV: Pulsatility index for vein, PVIV: Peak velocity index for vein, a/S: The ratio of velocity in atrial contraction to velocity in ventricular systole

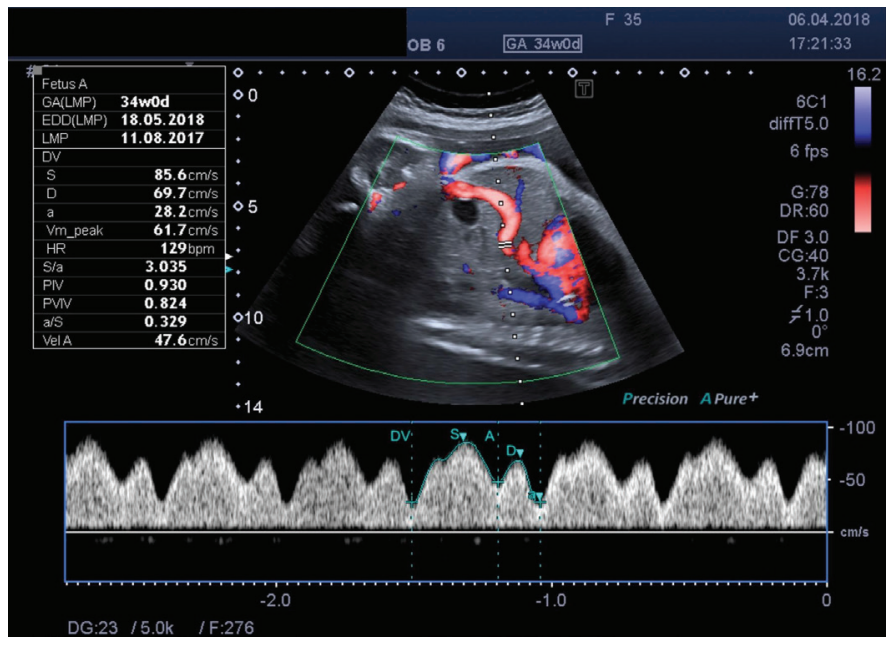

Figure 7. The measurement of ductus venosus flow velocity and indices 34 weeks' gestation of the same patients in figure 6 in the sagittal plane

DR: Dynamic range, DF: Dynamic frequency, CG: Color gain, $F$ : filter, DV: Ductus venosus, S: Velocity in ventricular contraction, D: Velocity in early ventricular diastole, a: Velocity in atrial systole, VmPeak: Time-averaged maximum velocity, S/a: The ratio of velocity in ventricular systole to velocity in atrial contraction, PIV: Pulsatility index for vein, PVIV: Peak velocity index for vein, a/S: The ratio of velocity in atrial contraction to velocity in ventricular systole

\section{Material and Methods}

Singleton, low-risk pregnancies fulfilling the inclusion criteria between 11 and 40 weeks gestation were included in this prospective study that took place between January 2016 and February 2018. Inclusion criteria were selected to ensure that the pregnancy was either uncomplicated or that there were no risk factors for maternal or fetal safety. Since the hospital is a tertiary care center, the patients were either from the urban or the rural territories of the city, which takes immigration from several parts of the country.

The written informed consent from the patients and the ethical approval from the Ethics Committee of the University of Health Sciences Turkey, Antalya Training and Research Hospital were obtained (approval number: 16/13, date: 02.11.2017).

Inclusion criteria were: (1) pregnancies with optimal visualization of the DV using a wideband color Doppler technique [advanced dynamic flow (ADF)]; (2) eventual Apgar score $\geq 8$; (3) birth weight $\geq 2500$ grams; (4) measurements taken from a single optimal waveform after obtaining 4 to 5 consecutive uniform Doppler velocity waveforms in the tracings with 2-3 cm/s sweep speed; (5) patients with normal amniotic fluid index; and (6) patients with normal screening tests.

Exclusion criteria were: (1) gestational diabetes; (2) multiple pregnancies; (3) preeclampsia; (4) maternal cardiac rhythm 
disturbances; (5) maternal smoking during pregnancy; (6) polyhydramnios or oligohydramnios; (7) fetal morphological abnormality; (8) intrauterine growth restriction; (9) macrosomia; (10) fetal stillbirth; (11) eventual Apgar score $<8$; and (12) fetuses with transient bradycardia (deceleration).

In all cases the equipment used for all examinations was a Toshiba Applio 500 system (TUS-A500, Toshiba Medical Systems Europe B.V., Zilverstraat 1, 2718 RP, Zoetermeer, the Netherlands) with a 2-6 MHz broadband convex transducer.

Measurements of DV flow velocities (S, v, D, a, VmPeak) and indices (PIV, PVIV, a/S, S/a) were performed using a spectral waveform. Isovolumetric relaxation velocity (IRV or DV v) was measured manually, since it was not inbuilt into the equipment capabilities. The preload and SIA indices were calculated using Microsoft Excel (Microsoft Corp., Santa Rosa, CA, USA). The still images were stored in the Sectra picture archiving and communication system (PACS) system (Sectra AB, Teknikringen 20, SE-583 30 Linköping, Sweden).

DV measurements were performed in all variants of the spectral waveform patterns of the DV flow, which were described recently by Gürses et al (9). Calculations were made either in the normal component of type 4 or type 5 flow patterns, or after the flow pattern returned to a classic pattern either in type 6 or 7 flow patterns.

Fetal age was estimated according to the last menstrual period. However, in case of discordance of $>7$ days between the age based on the last menstrual date and the age based on the biometry measures with ultrasonography, the gestational age was redated.

Doppler examinations are performed by a single experienced specialist (C.G.), certified for DV flow and Doppler examinations by the (Fetal Medicine Foundation ID: 127129; 137 Harley Street, London, W1G 6BG, United Kingdom). DV measurements were performed according to the criteria in the medical literature (10-13). A $1 \mathrm{~mm}$ wide sample gate was positioned over the isthmus and adjacent proximal section, where the aliasing occurs due to the accelerated jet flow. The wide-band color Doppler technique (ADF) was used for mapping the DV and placing the sample gate accurately in PD examinations to avoid contamination of the signal by adjacent veins during the PD tracings (Figure 2-7, Video 1-3).

The still images were stored in the Sectra (PACS) system (Sectra AB, Teknikringen 20, SE-583 30 Linköping, Sweden).

Toshiba Applio 500 system (TUS-A500, Toshiba Medical Systems Europe B.V., Zilverstraat 1, 2718 RP, Zoetermeer, the Netherlands) is used in all examinations with a $2-6 \mathrm{MHz}$ broadband convex transducer.

The acoustic output level was adjusted to a minimum following the as low as reasonably achievable principle and the maximum mechanical index was 1.1. Imaging parameters were dynamic range 70 , dynamic frequency 3.0 , and color gain 40 , color pulse repetition frequency 5-6 and color filter (F) 3-4. Sweep speed was $2-3 \mathrm{~cm} / \mathrm{s}$ in all of the trimesters and the Doppler filter was set between 90 and 140 in the first trimester of the pregnancy during the PD examinations.

\section{Statistical analysis}

Data were collected using Microsoft Excel for Windows (Microsoft, Redmond, WA, USA) and the analysis was performed using the Statistical Software for Social Sciences for Windows, version 17.0 (SPSS Inc., Chicago, IL, USA). Data are presented as mean \pm standard deviation. For statistical analysis, the distribution of each blood flow velocity and DV index was examined using scatter plots against the gestational age. Due to the descriptive nature of the study, no tests of statistical significance were performed.

\section{Results}

A total of 1279 singleton pregnancies between 11 and 40 weeks gestation were enrolled in this prospective, crosssectional study. The mean maternal age was $28.05 \pm 6.54$ years and the mean eventual birth weight was $3,294 \pm 448.5$ g. Median (range) gestational age was 22 (11-40) weeks and mean body mass index was $29.05 \pm 5.17$. The median (range) number of participants for each week of gestation was 35 (23-86).

Peak forward velocities were recorded and DV indices were calculated (Figure 1-7). The predicted reference ranges of the DV blood flow velocities and indices by gestational age are shown in Table 1-6. Predicted reference curves based on the $5^{\text {th }}$ and $95^{\text {th }}$ percentiles by gestational week were plotted and shown in Figure 8-10.

\section{Discussion}

After ultrasonographic velocimetry of fetal DV was described by Kiserud et al. (14) for the first time, there has been interest in establishing reference ranges for the measurements obtained. Several studies have published reference ranges for either the absolute flow velocities, which are insonation angledependent, or the indices, which are clinically preferred due to being the insonation angle-independent, for all weeks of pregnancies $(2-5,15)$.

Doppler assessment of DV should satisfy some criteria, which have previously been discussed in detail (1013). In the present study, these criteria were held constant in terms of user preset adjustment. In addition, wideband color Doppler technique was used to image the DV and to place the sample gate before performing measurements. The advantage of wideband color Doppler 
is that blooming is thought to be less problematic than when using the conventional narrowband technique. Blooming is the name given to an artefact of color Doppler where vessels appear larger than the true diameter due to aretfactual extension of the color signal beyond the vessel walls. Blooming artefact is the main disadvantage associated with visualization of the vascular structures due to a lack of lateral discrimination and it causes exaggerated or false positive vascular colorizing $(16,17)$. Blooming is particularly important when attempting to

Table 1. Predicted reference ranges for ductus venosus spectral Doppler absolute flow velocities from 11 to 20 weeks of gestation

\begin{tabular}{|c|c|c|c|c|c|c|}
\hline Week & Percentile & $\mathbf{S}$ & $\mathbf{v}$ & D & $\mathbf{a}$ & VmPeak \\
\hline \multirow{3}{*}{11} & 5 & 20.7 & 0 & 16.5 & 5.58 & 15.5 \\
\hline & 50 & 35.2 & 24.7 & 30.5 & 10 & 26.3 \\
\hline & 95 & 46.4 & 36.9 & 42.6 & 23 & 37.8 \\
\hline \multirow{3}{*}{12} & 5 & 23.9 & 0 & 21 & 6.2 & 17.6 \\
\hline & 50 & 37.0 & 24.2 & 31.8 & 10.9 & 27.6 \\
\hline & 95 & 51.3 & 40 & 47 & 20.3 & 39.4 \\
\hline \multirow{3}{*}{13} & 5 & 24.8 & 0 & 22.8 & 4.9 & 18.2 \\
\hline & 50 & 36.9 & 24.6 & 32.7 & 10.9 & 27.8 \\
\hline & 95 & 50.6 & 38.7 & 45.6 & 20.8 & 39.3 \\
\hline \multirow{3}{*}{14} & 5 & 30.3 & 0 & 27.7 & 5.4 & 23.2 \\
\hline & 50 & 43.3 & 30.5 & 38.7 & 11.9 & 33.3 \\
\hline & 95 & 58.3 & 41.9 & 50.4 & 18.4 & 43.5 \\
\hline \multirow{3}{*}{15} & 5 & 24.9 & 0 & 20.2 & 6.7 & 17.4 \\
\hline & 50 & 46.5 & 34.6 & 41.7 & 15.2 & 36.3 \\
\hline & 95 & 61.6 & 50.9 & 56.8 & 27.2 & 50.5 \\
\hline \multirow{3}{*}{16} & 5 & 29.4 & 19.6 & 26 & 9.7 & 22.9 \\
\hline & 50 & 52.6 & 39.7 & 47.2 & 17.9 & 41.4 \\
\hline & 95 & 60.9 & 51.2 & 56.7 & 32.1 & 50.6 \\
\hline \multirow{3}{*}{17} & 5 & 31.8 & 13.2 & 29.9 & 10 & 26.1 \\
\hline & 50 & 45.6 & 35.2 & 40.7 & 17.6 & 36.9 \\
\hline & 95 & 64.3 & 49.4 & 57.1 & 31.7 & 50.2 \\
\hline \multirow{3}{*}{18} & 5 & 34.9 & 18.6 & 32.6 & 10.9 & 27.6 \\
\hline & 50 & 52.9 & 41.8 & 50.3 & 21.8 & 43.5 \\
\hline & 95 & 66.9 & 53.1 & 61 & 35.7 & 54.6 \\
\hline \multirow{3}{*}{19} & 5 & 32.3 & 24.3 & 29.6 & 11.4 & 25.4 \\
\hline & 50 & 50.1 & 39.7 & 47.1 & 21.5 & 41.3 \\
\hline & 95 & 68.6 & 54.3 & 62 & 40 & 56.3 \\
\hline \multirow{3}{*}{20} & 5 & 30.1 & 5 & 28.1 & 11.2 & 25.1 \\
\hline & 50 & 49.4 & 39 & 46.7 & 24.8 & 40.3 \\
\hline & 95 & 74.4 & 57.3 & 70.2 & 40.3 & 61.6 \\
\hline
\end{tabular}

visualize the tiny or slow-flow blood vessels of the fetus. Blooming increases not only false vascularity but also wrong placement of the sample gate in PD tracings and causes prolonged examination time. Maiz et al. (10) demonstrated that a sonographer is required to perform an average of 80 examinations to achieve competence in the Doppler assessment of DV. One of the criteria of Maiz et al. (10) was to obtain measurements in a right ventral mid-sagittal view. However, it has been suggested that the main criterion should be to position the probe so that

Table 2. Predicted reference ranges for ductus venosus spectral Doppler absolute flow velocities from 21 to 30 weeks of gestation

\begin{tabular}{|c|c|c|c|c|c|c|}
\hline Week & Percentile & $\mathbf{S}$ & $\mathbf{v}$ & D & $\mathbf{a}$ & VmPeak \\
\hline \multirow{3}{*}{21} & 5 & 38.8 & 16.9 & 33.9 & 13.3 & 29.9 \\
\hline & 50 & 57.6 & 42.7 & 52.6 & 27.5 & 46.4 \\
\hline & 95 & 73 & 56.6 & 67.9 & 42.6 & 60.5 \\
\hline \multirow{3}{*}{22} & 5 & 39.7 & 22.1 & 35.4 & 15.9 & 31.1 \\
\hline & 50 & 55.1 & 42.7 & 51.4 & 26.6 & 45.5 \\
\hline & 95 & 73.7 & 61.2 & 66.1 & 46.6 & 61.1 \\
\hline \multirow{3}{*}{23} & 5 & 39.4 & 28.8 & 35.6 & 16.9 & 31.2 \\
\hline & 50 & 62 & 45 & 55.1 & 30.4 & 48.9 \\
\hline & 95 & 80 & 62.1 & 72.8 & 47.6 & 67.4 \\
\hline \multirow{3}{*}{24} & 5 & 56.3 & 0 & 49.3 & 25.6 & 45.5 \\
\hline & 50 & 64.5 & 50.6 & 61.5 & 34.4 & 53.5 \\
\hline & 95 & 81.5 & 63.3 & 73.4 & 50.6 & 66.6 \\
\hline \multirow{3}{*}{25} & 5 & 39.2 & 18.7 & 34.2 & 14.5 & 27.2 \\
\hline & 50 & 58.5 & 44.1 & 56.5 & 31.8 & 49.7 \\
\hline & 95 & 81.4 & 64.7 & 74.5 & 53.8 & 67.9 \\
\hline \multirow{3}{*}{26} & 5 & 42.1 & 25.6 & 37.3 & 18.2 & 32.4 \\
\hline & 50 & 58.2 & 43.2 & 52.9 & 30.9 & 46.6 \\
\hline & 95 & 77.3 & 59.7 & 72.7 & 49.2 & 64.6 \\
\hline \multirow{3}{*}{27} & 5 & 39 & 26.1 & 33.5 & 15.9 & 30.5 \\
\hline & 50 & 58.2 & 44.1 & 52.6 & 27.3 & 47.6 \\
\hline & 95 & 85.9 & 71 & 78.9 & 54.2 & 74.6 \\
\hline \multirow{3}{*}{28} & 5 & 31.3 & 20.4 & 28 & 13.9 & 23.8 \\
\hline & 50 & 62.6 & 48.6 & 59.1 & 37.6 & 53.5 \\
\hline & 95 & 76.9 & 62.5 & 72.4 & 50.6 & 65.8 \\
\hline \multirow{3}{*}{29} & 5 & 41.7 & 28 & 35.7 & 19.1 & 33.4 \\
\hline & 50 & 62.6 & 48.5 & 57.6 & 38.7 & 52 \\
\hline & 95 & 79.4 & 66.7 & 74.1 & 51.3 & 68.9 \\
\hline \multirow{3}{*}{30} & 5 & 39.5 & 24.7 & 35.3 & 14.5 & 31.6 \\
\hline & 50 & 58.5 & 43.6 & 54.2 & 32.6 & 48 \\
\hline & 95 & 92 & 77.1 & 88.2 & 55.9 & 79.5 \\
\hline \multicolumn{7}{|c|}{$\begin{array}{l}\text { S: Velocity in ventricular contraction, v: Velocity in end-systolic ventricular } \\
\text { relaxation, D: Velocity in early ventricular diastole, a: Velocity in atrial } \\
\text { systole, VmPeak: Time-averaged maximum velocity }\end{array}$} \\
\hline
\end{tabular}


the blood flow direction is towards the transducer plane which will result in an insonation angle close to 0 (Figure 1, Video 1). The wideband color Doppler technique allows visualization of the intrahepatic umbilical vein (UV), the left portal vein (LPV) and the portal sinus (PS) not only in ventral but also in dorsal approach (Figure 1, Video 1).

Even though Martins and Kiserud (13) suggested using a sample gate setting of $2-5 \mathrm{~mm}$ wide in the second half of

Table 3. Predicted reference ranges for ductus venosus spectral Doppler absolute flow velocities from 31 to 40 weeks of gestation

\begin{tabular}{|c|c|c|c|c|c|c|}
\hline Week & Percentile & $\mathbf{S}$ & $\mathbf{v}$ & D & $\mathbf{a}$ & VmPeak \\
\hline \multirow{3}{*}{31} & 5 & 37.4 & 26.2 & 35.7 & 21.8 & 31.9 \\
\hline & 50 & 57.8 & 44.5 & 53.8 & 32.2 & 49.5 \\
\hline & 95 & 77.9 & 65.4 & 72.6 & 49.9 & 66.2 \\
\hline \multirow{3}{*}{32} & 5 & 30.2 & 25.7 & 28.2 & 14.6 & 25.9 \\
\hline & 50 & 57.4 & 43.2 & 51.6 & 30.2 & 47.9 \\
\hline & 95 & 82.2 & 64.3 & 76.3 & 48.9 & 68.8 \\
\hline \multirow{3}{*}{33} & 5 & 40.3 & 32 & 37.4 & 20 & 35.5 \\
\hline & 50 & 57.9 & 46.6 & 52.5 & 33.9 & 49.0 \\
\hline & 95 & 89.4 & 72 & 84.4 & 57.7 & 76.8 \\
\hline \multirow{3}{*}{34} & 5 & 30.4 & 24.8 & 28.3 & 16.8 & 26.8 \\
\hline & 50 & 59.2 & 41.5 & 53.2 & 30.1 & 47.7 \\
\hline & 95 & 82.6 & 58.8 & 73.8 & 49.9 & 65.2 \\
\hline \multirow{3}{*}{35} & 5 & 30.9 & 19.9 & 25.7 & 15 & 25.6 \\
\hline & 50 & 53.6 & 40.7 & 50.6 & 31.6 & 46.3 \\
\hline & 95 & 86 & 65.3 & 78.2 & 56.4 & 71 \\
\hline \multirow{3}{*}{36} & 5 & 32.6 & 27.6 & 32.3 & 18.5 & 29.8 \\
\hline & 50 & 54 & 42 & 49.5 & 31.3 & 44.6 \\
\hline & 95 & 80.3 & 65 & 75 & 52.2 & 68.1 \\
\hline \multirow{3}{*}{37} & 5 & 29.6 & 26.1 & 28 & 19.1 & 26.3 \\
\hline & 50 & 57.6 & 43.1 & 52 & 34.4 & 46.9 \\
\hline & 95 & 79.9 & 70.6 & 74.7 & 55.5 & 62.4 \\
\hline \multirow{3}{*}{38} & 5 & 32.8 & 23.2 & 29.7 & 14.3 & 26.3 \\
\hline & 50 & 52.9 & 44.1 & 49.4 & 31.9 & 46.2 \\
\hline & 95 & 86.4 & 65.4 & 73.3 & 51.3 & 67.3 \\
\hline \multirow{3}{*}{39} & 5 & 29.9 & 23.9 & 27.1 & 15.7 & 24.7 \\
\hline & 50 & 49.9 & 40.6 & 46.7 & 31.8 & 41.8 \\
\hline & 95 & 74 & 61 & 66.6 & 47.3 & 61.9 \\
\hline \multirow{3}{*}{40} & 5 & 32 & 22.7 & 27.8 & 16.4 & 26.5 \\
\hline & 50 & 43.1 & 37 & 39.7 & 31.6 & 39.7 \\
\hline & 95 & 72.1 & 57.2 & 64.2 & 44.9 & 59.1 \\
\hline
\end{tabular}

S: Velocity in ventricular contraction, v: Velocity in end-systolic ventricular relaxation, D: Velocity in early ventricular diastole, a: Velocity in atrial systole, VmPeak: Time-averaged maximum velocity the pregnancy, in the present study a $1 \mathrm{~mm}$ wide sample gate was used consistently and for measurements made at each gestational week to allow direct comparison with measurements made in other gestational weeks and to avoid signal contamination from the hepatic veins and inferior vena cava.

Despite the difficulty of attempting to ensure an insonation angle of the vessel of 0 degrees, the absolute flow velocities

Table 4. Predicted reference ranges for ductus venosus Doppler indices from 11 to 20 weeks of gestation

\begin{tabular}{|c|c|c|c|c|c|c|c|}
\hline Week & Percentile & PIV & PVIV & $\mathbf{a} / \mathbf{S}$ & $\mathbf{S} / \mathbf{a}$ & $\begin{array}{l}\text { Preolad } \\
\text { index }\end{array}$ & $\begin{array}{l}\text { SIA } \\
\text { index }\end{array}$ \\
\hline \multirow{3}{*}{11} & 5 & 0.52 & 0.43 & 0.17 & 1.77 & 0.43 & 0.69 \\
\hline & 50 & 0.93 & 0.80 & 0.29 & 3.41 & 0.71 & 0.94 \\
\hline & 95 & 1.13 & 1.03 & 0.56 & 5.62 & 0.82 & 1.12 \\
\hline \multirow{3}{*}{12} & 5 & 0.62 & 0.55 & 0.18 & 2.05 & 0.51 & 0.75 \\
\hline & 50 & 0.94 & 0.81 & 0.30 & 3.33 & 0.7 & 1 \\
\hline & 95 & 1.15 & 1.01 & 0.48 & 5.43 & 0.81 & 1.25 \\
\hline \multirow{3}{*}{13} & 5 & 0.59 & 0.51 & 0.15 & 1.93 & 0.48 & 0.77 \\
\hline & 50 & 0.92 & 0.78 & 0.31 & 3.19 & 0.69 & 0.98 \\
\hline & 95 & 1.14 & 0.99 & 0.51 & 6.34 & 0.84 & 1.31 \\
\hline \multirow{3}{*}{14} & 5 & 0.69 & 0.61 & 0.13 & 2.24 & 0.55 & 0.81 \\
\hline & 50 & 0.95 & 0.83 & 0.27 & 3.65 & 0.73 & 1 \\
\hline & 95 & 1.2 & 1.03 & 0.44 & 7.34 & 0.86 & 1.24 \\
\hline \multirow{3}{*}{15} & 5 & 0.61 & 0.53 & 0.22 & 2.01 & 0.5 & 0.75 \\
\hline & 50 & 0.87 & 0.73 & 0.33 & 2.98 & 0.66 & 0.93 \\
\hline & 95 & 1.05 & 0.90 & 0.49 & 4.50 & 0.78 & 1.17 \\
\hline \multirow{3}{*}{16} & 5 & 0.51 & 0.45 & 0.21 & 1.77 & 0.43 & 0.72 \\
\hline & 50 & 0.75 & 0.65 & 0.39 & 2.55 & 0.61 & 0.88 \\
\hline & 95 & 1.04 & 0.92 & 0.56 & 4.70 & 0.79 & 1.09 \\
\hline \multirow{3}{*}{17} & 5 & 0.4 & 0.36 & 0.26 & 1.57 & 0.36 & 0.65 \\
\hline & 50 & 0.74 & 0.66 & 0.4 & 2.46 & 0.59 & 0.85 \\
\hline & 95 & 1.04 & 0.87 & 0.63 & 3.73 & 0.73 & 1.1 \\
\hline \multirow{3}{*}{18} & 5 & 0.38 & 0.34 & 0.25 & 1.52 & 0.34 & 0.64 \\
\hline & 50 & 0.68 & 0.61 & 0.44 & 2.26 & 0.56 & 0.83 \\
\hline & 95 & 1.02 & 0.84 & 0.65 & 4.04 & 0.74 & 1.12 \\
\hline \multirow{3}{*}{19} & 5 & 0.41 & 0.36 & 0.32 & 1.56 & 0.36 & 0.66 \\
\hline & 50 & 0.71 & 0.62 & 0.41 & 2.42 & 0.58 & 0.82 \\
\hline & 95 & 0.87 & 0.74 & 0.63 & 3.08 & 0.67 & 0.95 \\
\hline \multirow{3}{*}{20} & 5 & 0.34 & 0.32 & 0.3 & 1.43 & 0.30 & 0.67 \\
\hline & 50 & 0.62 & 0.56 & 0.48 & 2.07 & 0.52 & 0.79 \\
\hline & 95 & 0.96 & 0.82 & 0.69 & 3.31 & 0.69 & 1.09 \\
\hline
\end{tabular}

PIV: Pulsatility index for veins, PVIV: Peak velocity index for veins, a/S: The ratio of velocity in atrial contraction to velocity in ventricular systole, $\mathrm{S} / \mathrm{a}$ : The ratio of velocity in ventricular systole to velocity in atrial contraction, Preload index: $(\mathrm{S}-\mathrm{a}) / \mathrm{S}$, SIA index: $\mathrm{S} /(\mathrm{a}+\mathrm{v})$, Atrial preload index: $(\mathrm{S}+\mathrm{D}) /(\mathrm{a}+\mathrm{v})$, Atrial afterload index: $(a+v) /(S+D)$ 
were measured in DV at 0 or close to 0 degrees in most cases and certainly below 30 degree of insonation in the present study. Wideband color Doppler was also useful in determining the actual blood flow direction, so thereby deciding the angle of insonation. DV absolute flow velocities are increased in anaemia and diseases affecting the liver parenchyma $(18,19)$, and the angle of insonation is critical for absolute flow velocity measurements in DV. In the present study, angle-independent indices were measured

Table 5. Predicted reference ranges for ductus venosus Doppler indices from 21 to 30 weeks of gestation

\begin{tabular}{|c|c|c|c|c|c|c|c|}
\hline Week & Percentile & PIV & PVIV & $\mathbf{a} / \mathbf{S}$ & $\mathbf{S} / \mathbf{a}$ & $\begin{array}{l}\text { Preolad } \\
\text { index }\end{array}$ & \begin{tabular}{|l|} 
SIA \\
index
\end{tabular} \\
\hline \multirow{3}{*}{21} & 5 & 0.36 & 0.34 & 0.34 & 1.48 & 0.32 & 0.64 \\
\hline & 50 & 0.63 & 0.55 & 0.48 & 2.05 & 0.51 & 0.81 \\
\hline & 95 & 0.85 & 0.74 & 0.67 & 2.89 & 0.65 & 0.97 \\
\hline \multirow{3}{*}{22} & 5 & 0.32 & 0.29 & 0.33 & 1.42 & 0.29 & 0.61 \\
\hline & 50 & 0.61 & 0.55 & 0.49 & 2 & 0.5 & 0.79 \\
\hline & 95 & 0.87 & 0.75 & 0.7 & 2.99 & 0.67 & 1 \\
\hline \multirow{3}{*}{23} & 5 & 0.37 & 0.34 & 0.33 & 1.48 & 0.32 & 0.65 \\
\hline & 50 & 0.59 & 0.53 & 0.51 & 1.93 & 0.48 & 0.78 \\
\hline & 95 & 0.88 & 0.79 & 0.67 & 2.96 & 0.66 & 1.03 \\
\hline \multirow{3}{*}{24} & 5 & 0.38 & 0.35 & 0.42 & 1.51 & 0.34 & 0.65 \\
\hline & 50 & 0.56 & 0.48 & 0.53 & 1.86 & 0.46 & 0.79 \\
\hline & 95 & 0.73 & 0.65 & 0.65 & 2.36 & 0.58 & 0.89 \\
\hline \multirow{3}{*}{25} & 5 & 0.33 & 0.3 & 0.3 & 1.42 & 0.29 & 0.64 \\
\hline & 50 & 0.55 & 0.48 & 0.53 & 1.85 & 0.46 & 0.75 \\
\hline & 95 & 0.9 & 0.78 & 0.7 & 3.23 & 0.69 & 1.07 \\
\hline \multirow{3}{*}{26} & 5 & 0.28 & 0.26 & 0.36 & 1.35 & 0.26 & 0.63 \\
\hline & \begin{tabular}{|l|}
50 \\
\end{tabular} & 0.55 & 0.47 & 0.56 & 1.86 & 0.43 & 0.73 \\
\hline & 95 & 0.82 & 0.7 & 0.73 & 3.51 & 0.64 & 1.01 \\
\hline \multirow{3}{*}{27} & 5 & 0.37 & 0.34 & 0.32 & 1.48 & 0.32 & 0.65 \\
\hline & 50 & 0.61 & 0.55 & 0.49 & 2 & 0.5 & 0.83 \\
\hline & 95 & 0.93 & 0.76 & 0.67 & 3.07 & 0.67 & 1.05 \\
\hline \multirow{3}{*}{28} & 5 & 0.24 & 0.23 & 0.42 & 1.29 & 0.23 & 0.59 \\
\hline & 50 & 0.55 & 0.49 & 0.54 & 1.82 & 0.45 & 0.78 \\
\hline & \begin{tabular}{|l|}
95 \\
\end{tabular} & 0.73 & 0.64 & 0.77 & 2.34 & 0.57 & 0.94 \\
\hline \multirow{3}{*}{29} & 5 & 0.32 & 0.28 & 0.43 & 1.4 & 0.28 & 0.63 \\
\hline & 50 & 0.5 & 0.43 & 0.58 & 1.71 & 0.41 & 0.73 \\
\hline & 95 & 0.73 & 0.72 & 0.71 & 2.33 & 0.56 & 0.92 \\
\hline \multirow{3}{*}{30} & 5 & 0.26 & 0.24 & 0.33 & 1.32 & 0.24 & 0.61 \\
\hline & 50 & 0.5 & 0.44 & 0.56 & 1.77 & 0.44 & 0.73 \\
\hline & 95 & 0.92 & 0.77 & 0.75 & 3.01 & 0.66 & 1.07 \\
\hline
\end{tabular}

PIV: Pulsatility index for veins, PVIV: Peak velocity index for veins, a/S: The ratio of velocity in atrial contraction to velocity in ventricular systole, $\mathrm{S} / \mathrm{a}$ : The ratio of velocity in ventricular systole to velocity in atrial contraction, Preload index: (S-a)/S, SIA index: $\mathrm{S} /(\mathrm{a}+\mathrm{v})$, Atrial preload index: $(\mathrm{S}+\mathrm{Ds}) /(\mathrm{a}+\mathrm{v})$, Atrial afterload index: $(a+v) /(S+D)$ simultaneously with the absolute flow velocities by the inbuilt equipment software. The flow is at maximum velocity when the atrial pressure is minimum during the " $\mathrm{S}$ " and " $\mathrm{D}$ " peaks during ventricular systole and early ventricular diastole, respectively (Figure 1) and the flow is at minimum velocity when the atrial pressure is maximum during the " $\mathrm{v}$ " and "a" nadirs during end-systolic ventricular relaxation and atrial systole (Figure 1) (7). In daily practice, the PIV is clinically the most widely utilized (7). However, PIV is thought to give

Table 6. Predicted reference ranges for ductus venosus Doppler indices from 31 to 40 weeks of gestation

\begin{tabular}{|c|c|c|c|c|c|c|c|}
\hline Week & Percentile & PIV & PVIV & $\mathbf{a} / \mathbf{S}$ & $\mathbf{S} / \mathbf{a}$ & $\begin{array}{l}\text { Preolad } \\
\text { index }\end{array}$ & $\begin{array}{l}\text { SIA } \\
\text { index }\end{array}$ \\
\hline \multirow{3}{*}{31} & 5 & 0.29 & 0.26 & 0.42 & 1.36 & 0.26 & 0.61 \\
\hline & 50 & 0.48 & 0.43 & 0.6 & 1.65 & 0.4 & 0.74 \\
\hline & 95 & 0.73 & 0.65 & 0.73 & 2.36 & 0.57 & 0.89 \\
\hline \multirow{3}{*}{32} & 5 & 0.32 & 0.29 & 0.34 & 1.4 & 0.29 & 0.63 \\
\hline & 50 & 0.48 & 0.44 & 0.6 & 1.66 & 0.39 & 0.74 \\
\hline & 95 & 0.84 & 0.72 & 0.71 & 2.92 & 0.65 & 0.92 \\
\hline \multirow{3}{*}{33} & 5 & 0.15 & 0.14 & 0.34 & 1.17 & 0.14 & 0.56 \\
\hline & 50 & 0.46 & 0.42 & 0.6 & 1.65 & 0.4 & 0.74 \\
\hline & 95 & 0.89 & 0.8 & 0.85 & 2.92 & 0.65 & 1.02 \\
\hline \multirow{3}{*}{34} & 5 & 0.21 & 0.2 & 0.35 & 1.24 & 0.19 & 0.58 \\
\hline & 50 & 0.49 & 0.46 & 0.58 & 1.71 & 0.42 & 0.75 \\
\hline & 95 & 0.86 & 0.73 & 0.8 & 2.79 & 0.64 & 1.04 \\
\hline \multirow{3}{*}{35} & 5 & 0.2 & 0.19 & 0.36 & 1.24 & 0.2 & 0.57 \\
\hline & 50 & 0.5 & 0.45 & 0.58 & 1.7 & 0.41 & 0.74 \\
\hline & 95 & 0.83 & 0.78 & 0.8 & 2.76 & 0.63 & 1.02 \\
\hline \multirow{3}{*}{36} & 5 & 0.15 & 0.14 & 0.38 & 1.16 & 0.14 & 0.56 \\
\hline & 50 & 0.46 & 0.42 & 0.6 & 1.66 & 0.4 & 0.7 \\
\hline & 95 & 0.79 & 0.73 & 0.85 & 2.63 & 0.61 & 0.94 \\
\hline \multirow{3}{*}{37} & 5 & 0.11 & 0.1 & 0.39 & 1.11 & 0.1 & 0.54 \\
\hline & 50 & 0.5 & 0.44 & 0.6 & 1.66 & 0.4 & 0.7 \\
\hline & 95 & 0.84 & 0.74 & 0.89 & 2.52 & 0.6 & 0.95 \\
\hline \multirow{3}{*}{38} & 5 & 0.14 & 0.13 & 0.36 & 1.15 & 0.13 & 0.56 \\
\hline & 50 & 0.4 & 0.36 & 0.64 & 1.55 & 0.36 & 0.69 \\
\hline & 95 & 0.83 & 0.76 & 0.86 & 2.71 & 0.62 & 1 \\
\hline \multirow{3}{*}{39} & 5 & 0.09 & 0.08 & 0.34 & 1.1 & 0.08 & 0.53 \\
\hline & 50 & 0.44 & 0.39 & 0.64 & 1.54 & 0.35 & 0.68 \\
\hline & 95 & 0.94 & 0.76 & 0.9 & 2.87 & 0.65 & 1.06 \\
\hline \multirow{3}{*}{40} & 5 & 0.18 & 0.17 & 0.44 & 1.19 & 0.16 & 0.55 \\
\hline & 50 & 0.41 & 0.38 & 0.62 & 1.59 & 0.37 & 0.67 \\
\hline & 95 & 0.72 & 0.7 & 0.83 & 2.23 & 0.55 & 0.89 \\
\hline
\end{tabular}

PIV: Pulsatility index for veins, PVIV: Peak velocity index for veins, a/S: The ratio of velocity in atrial contraction to velocity in ventricular systole, $\mathrm{S} / \mathrm{a}$ : The ratio of velocity in ventricular systole to velocity in atrial contraction, Preload index: (S-a)/S, SIA index: $\mathrm{S} /(\mathrm{a}+\mathrm{v})$, Atrial preload index: $(\mathrm{S}+\mathrm{D}) /(\mathrm{a}+\mathrm{v})$, Atrial afterload index: $(a+v) /(S+D)$ 
an incomplete reflection of cardiac function, since relative changes in $\mathrm{v}$ - and D-wave velocities are not well represented (15) (Figure 1).

The afferent system of the fetal precordial venous system includes the intrahepatic UV, the LPV, the DV, the right portal vein (RPV) and the main portal vein. The PS is the L-shaped formation at the confluence of the LPV and RPV (20-22). The DV arises from the PS, just before turning at close to $90^{\circ}$ to the right (Figure 11,12) to create the pars transversa of the PS. The DV connects the LPV to the subdiaphragmatic vestibulum of the inferior vena cava, where the left and middle hepatic veins also connect $(21,22)$. Maternal oxygenated blood in the LPV is shunted through the DV and directed towards the left atrium via the foramen ovale (18-20). The DV is an essential component of the classical "via Sinistra" pathway (22) and thus the myocardium and cerebral circulations receive more oxygenated and higher nutritional blood from the placenta.

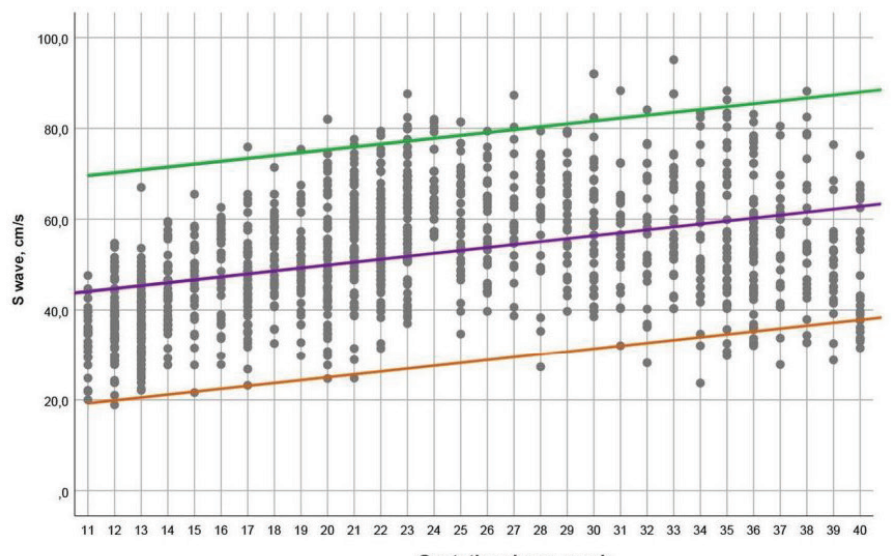

Gestational age, week

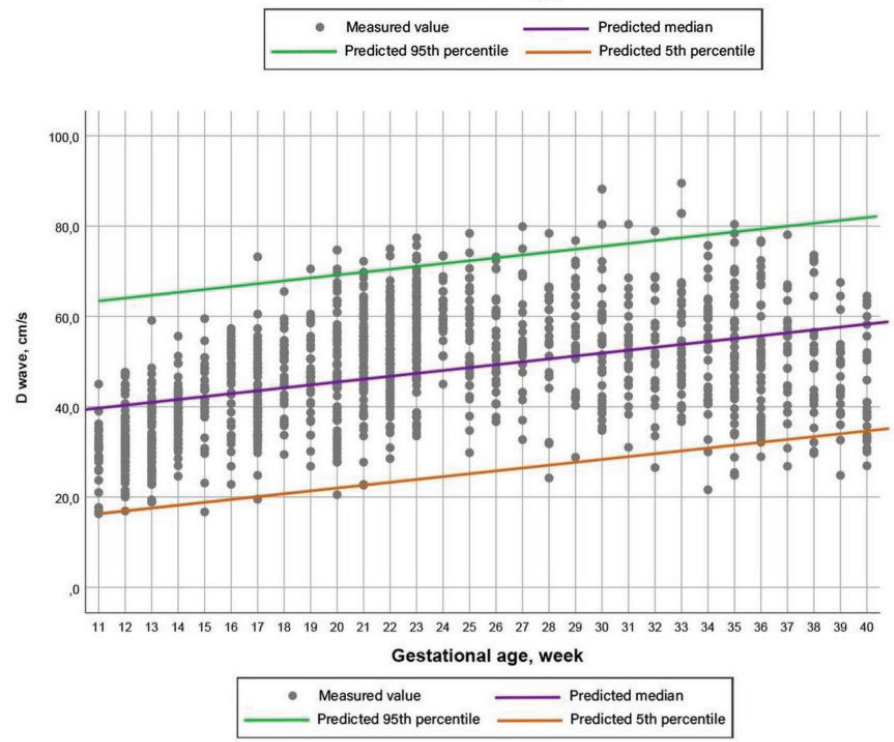

Blood flow velocities of the DV in a cardiac cycle change according to the weeks of pregnancy because of some physiologic properties of the fetal circulation. For example, the human DV at 13-17 weeks of gestational age has novel structural features distinct from those of other blood vessels (23). Umbilical blood flow also decreases with gestational age and at 28 to 32 weeks, the shunting through the DV reaches the minimum $(22,24)$. It has also been shown that the fraction of combined cardiac output directed to the placenta reduces after 34 weeks (24). When establishing reference ranges, the study population is of key importance, including when assessing reference values for blood flow velocities of the DV (25). The most difficult period to measure the patients was towards the end of pregnancy, especially between 38 and 40 weeks, since the proportion delivering by Caesarean section was much greater than those delivering by so-called "normal vaginal delivery", unfortunately.
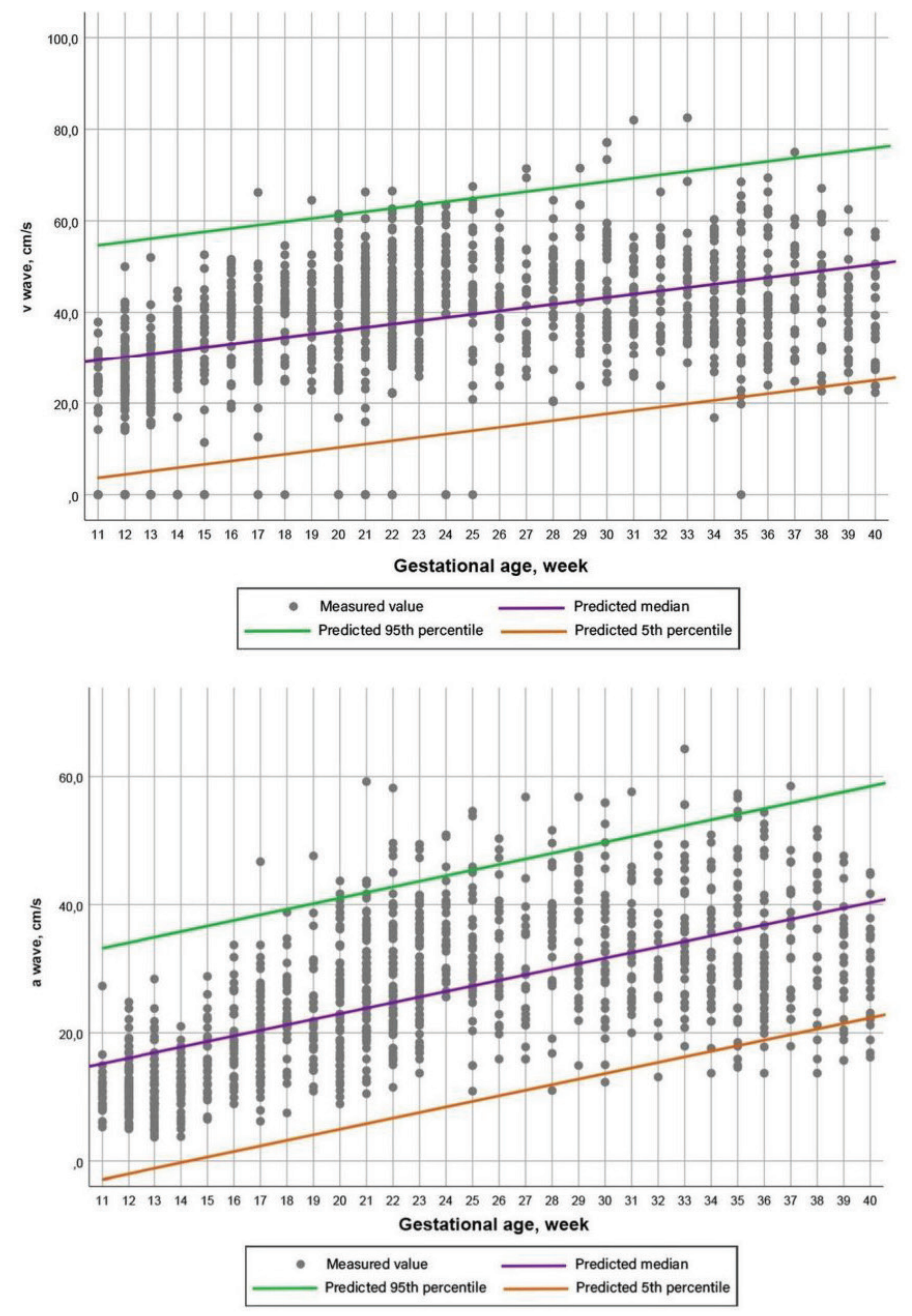

Figure 8. The scatter plots graphics for $S, \mathrm{v}, \mathrm{D}$, a wave $(\mathrm{cm} / \mathrm{s})$ against the gestational age 


\section{Study limitation}

There are some limitations to the present study. The number of patients for each week of pregnancy was different, since the numbers of women with some indications are more likely to be scanned in a given set of gestational weeks than other weeks and timings. For example, patients in the first trimester are sent for the double screening test or in the second trimester undergo anomaly screening and are thus referred more frequently. However, the number of patients assessed in the present study was at least 25 .

Turan et al. (3) studied the reference ranges of DV in 902 velocity wave ratios of pregnant women. The data was gathered retrospectively, obtained from two different fetal medicine centers, and scans were performed to a fixed protocol but by several sonographers and physicians. In addition, details of the ultrasonography equipment were also not. It is also well-known that ultrasonography is the most operator-dependent imaging

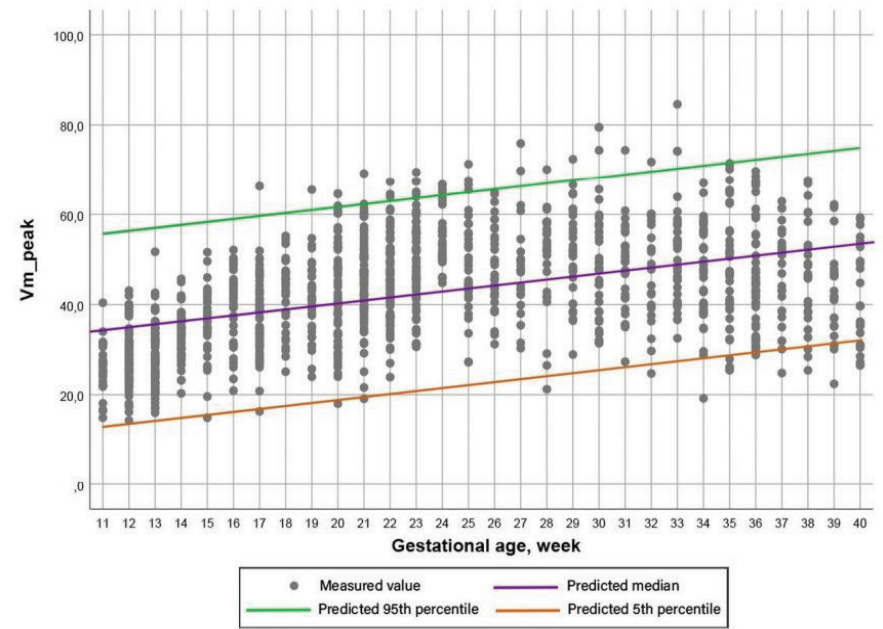

modality. Therefore strengths of our study include: the largest patient population in the medical literature; being performed prospectively; using a single piece of ultrasonographic equipment with the same preset adjustments; being single center: and all scans were performed by a single specialist operator with experience in fetal imaging. The measurements were estimated either in the classic spectral Doppler pattern of the DV or, to the best of our knowledge, for the first time in the medical literature in the variants of the spectral Doppler waveforms, which were described recently (9). In contrast to earlier studies, the wideband color Doppler technique (ADF, Toshiba) was used to visualize the slow flow fetal vessels without blooming artefact, which was used to locate the DV and to place the sample gates. This technique allowed collection of faster spectral waveforms of the DV and more accurate and reproducible measurements.

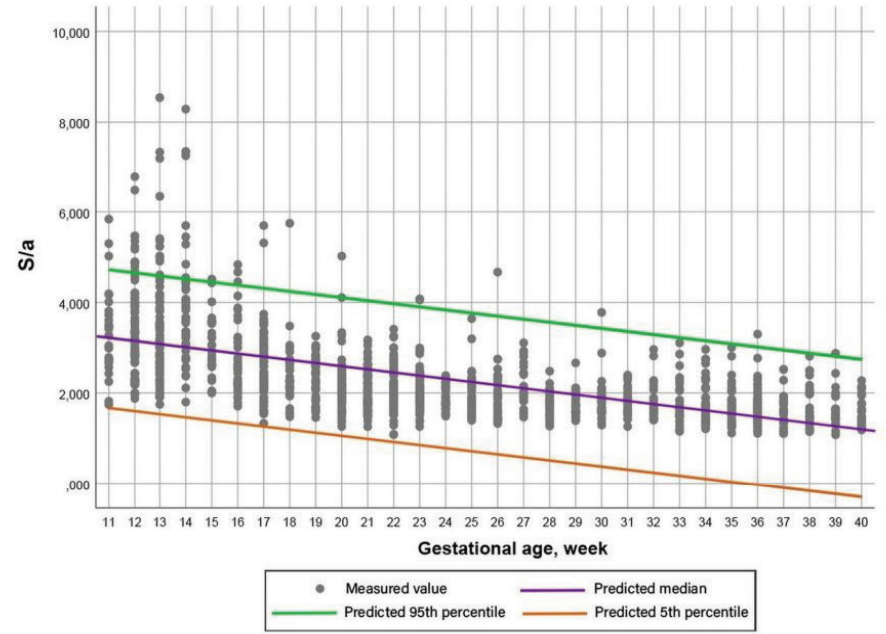

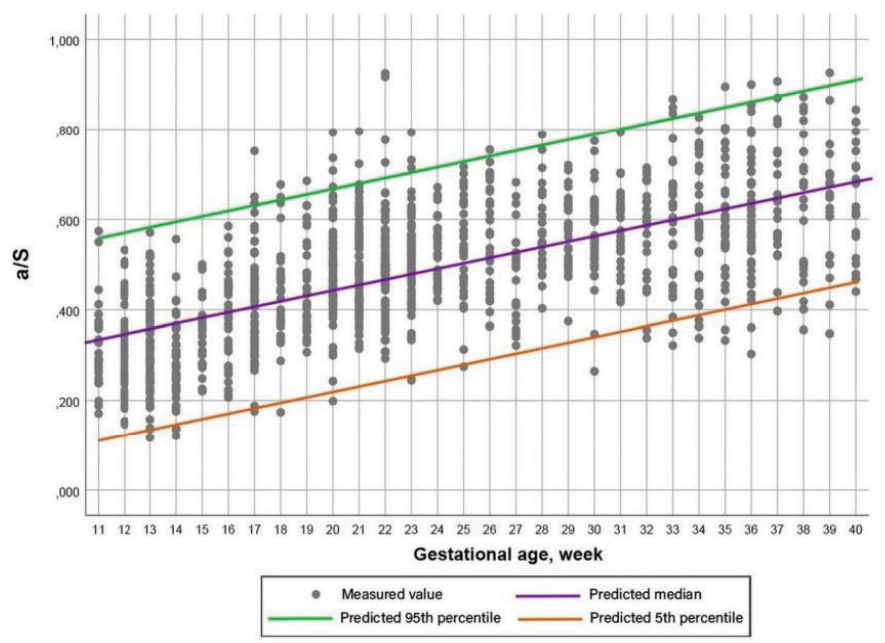

Figure 9. The scatter plots graphic for VmPeak wave $(\mathrm{cm} / \mathrm{s}), \mathrm{S} / \mathbf{a}$ and $\mathrm{a} / \mathrm{S}$ ratios against the gestational age

VmPeak: Time-averaged maximum velocity, S/a: The ratio of velocity in ventricular systole to velocity in atrial contraction, a/S: The ratio of velocity in atrial contraction to velocity in ventricular systole 

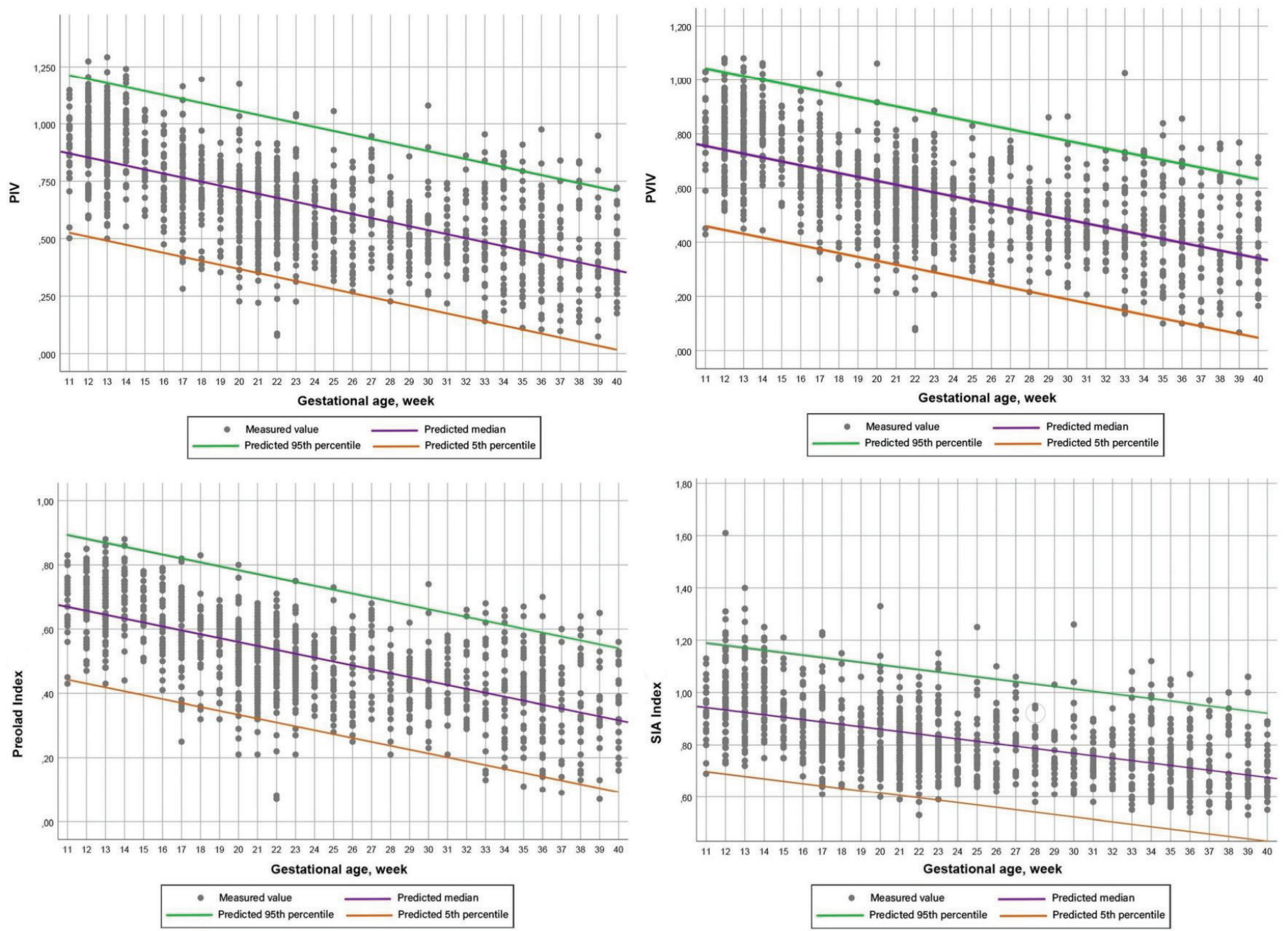

Figure 10. The scatter plots graphic for PIV, PVIV, preload and SIA indexes against the gestational age PIV: Pulsatility index for vein, PVIV: Peak velocity index for vein, SIA: $S /(a+v)$

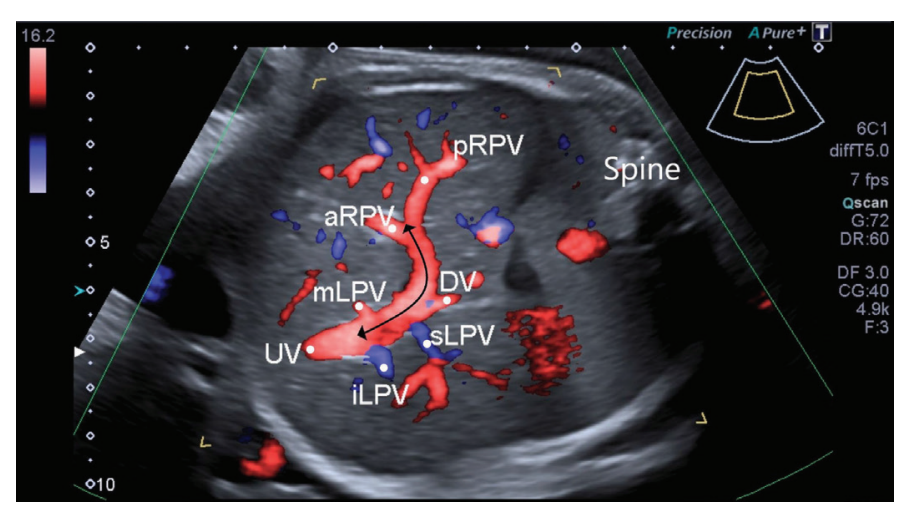

Figure 11. Afferent precordial venous system in an oblique axial color Doppler image

UV: Umbilical vein, DV: Ductus venosus, Curved black line: Portal sinus, mLPV: Medial branch of left portal vein, aRPV: Anterior branch of the right portal vein, pRPV: Posterior branch of the right portal vein

\section{Conclusion}

The advance in ultrasound technology has allowed easier mapping of the DV and collection of more reproducible measurements and so there was a need for re-establishment of reference ranges for DV velocities. This study has reported normal reference ranges for absolute flow velocities of $S$, $\mathrm{v}, \mathrm{D}, \mathrm{a}$ and $\mathrm{VmPeak}$ and indices, which were derived from velocities using a wideband Doppler technique, in the largest patient population so far. The study was undertaken prospectively in a single tertiary care center by a single experienced operator and can be used for detection and follow up fetal flow dynamics. 


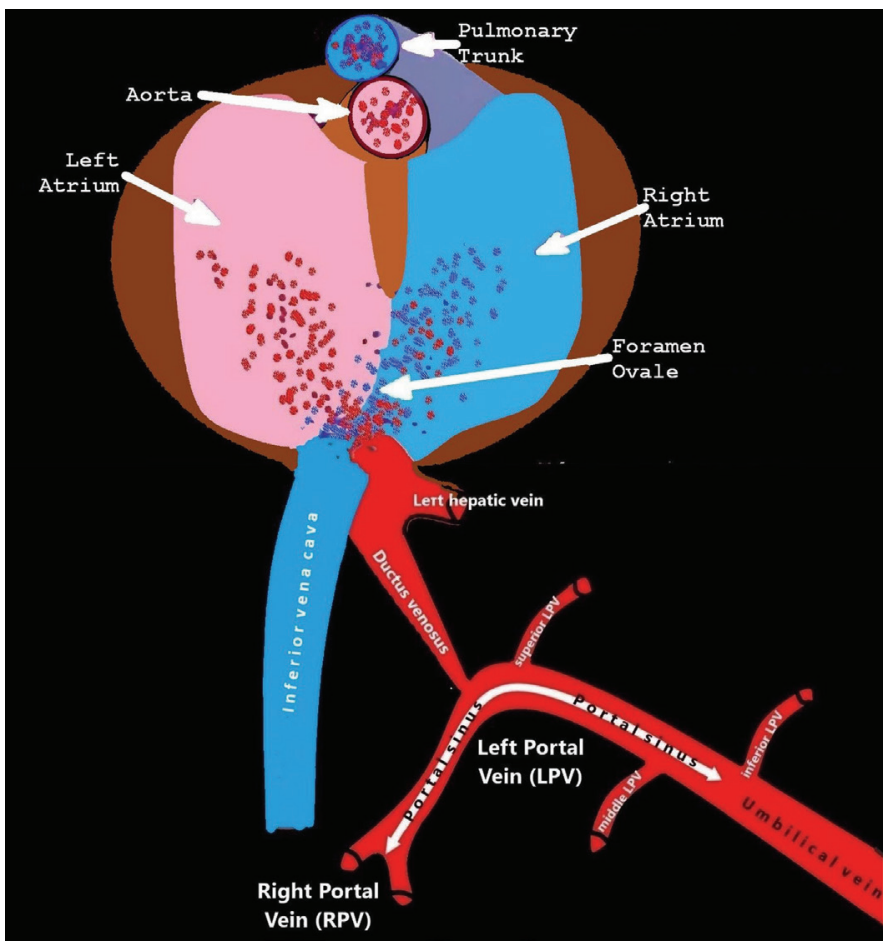

Figure 12. Flow distribution through the foramen ovale and the afferent precordial venous system in a painted illustration

Video 1. The spectral Doppler waveform of ductus venosus blood flow at 12 weeks gestation

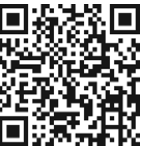

https://www.doi.org/10.4274/jtgga.galenos.2021.2020.0232.video1

Video 2. The spectral Doppler waveform of ductus venosus blood flow at 34 weeks gestation in the oblique transverse plane

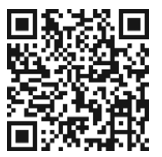

https://www.doi.org/10.4274/jtgga.galenos.2021.2020.0232.video2

Video 3. The spectral Doppler waveform of ductus venosus blood flow at 34 weeks gestation of the same patients in figure 6 in the sagittal plane

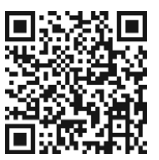

https://www.doi.org/10.4274/jtgga.galenos.2021.2020.0232.video3
Ethics Committee Approval: The written informed consent from the patients and the ethical approval from the Ethics Committee of the University of Health Sciences Turkey, Antalya Training and Research Hospital were obtained (approval number: 16/13, date: 02.11.2017).

Informed Consent: The written informed consent from the patients were obtained.

Peer-review: Externally peer-reviewed.

Author Contributions: Surgical and Medical Practices: C.G.; Concept: B.K., O.E.; Design: O.E., B.S.I.; Data Collection or Processing: C.G.; Analysis or Interpretation: B.K., C.K.; Literature Search: B.S.I.; Writing: C.G., C.K.

Conflict of Interest: No conflict of interest is declared by the authors.

Financial Disclosure: The authors declared that this study received no financial support.

\section{References}

1. Mone F, McAuliffe FM, Ong S. The clinical application of Doppler ultrasound in obstetrics. The Obstetrician \& Gynaecologist 2015; 17: 13-9.

2. Kalayci H, Yilmaz Baran Ş, Doğan Durdağ G, Yetkinel S, Alemdaroğlu S, Özdoğan S, et al. Reference values of the ductus venosus pulsatility index for pregnant women between 11 and $13+6$ weeks of gestation. J Matern Fetal Neonatal Med 2020; 33: 1134-9.

3. Turan OM, Turan S, Sanapo L, Willruth A, Berg C, Gembruch U, et al. Reference ranges for ductus venosus velocity ratios in pregnancies with normal outcomes. J Ultrasound Med 2014; 33: 329-36.

4. Kessler J, Rasmussen S, Hanson M, Kiserud T. Longitudinal reference ranges for ductus venosus flow velocities and waveform indices. Ultrasound Obstet Gynecol 2006; 28: 890-8.

5. Bahlmann F, Wellek S, Reinhardt I, Merz E, Steiner E, Welter C. Reference values of ductus venosus flow velocities and calculated waveform indices. Prenat Diagn 2000; 20: 623-34.

6. DeVore GR, Horenstein J. Ductus venosus index: a method for evaluating right ventricular preload in the second-trimester fetus Ultrasound Obstet Gynecol 1993; 3: 338-442.

7. Seravalli V, Miller JL, Block-Abraham D, Baschat AA. Ductus venosus Doppler in the assessment of fetal cardiovascular health: an updated practical approach. Acta Obstet Gynecol Scand 2016; 95: 635-44.

8. Picconi JL, Kruger M, Mari G. Ductus venosus S-wave/isovolumetric A-wave (SIA) index and A-wave reversed flow in severely premature growth-restricted fetuses. J Ultrasound Med 2008; 27: 1283-89.

9. Gürses C, Karadağ B, İsenlik BST. Normal variants of ductus venosus spectral Doppler flow patterns in normal pregnancies. J Matern Fetal Neonatal Med 2020; 33: 1288-94.

10. Maiz N, Kagan KO, Milovanovic Z, Nicolaides KH. Learning curve for Doppler assessment of ductus venosus flow at $11+0$ to $13+6$ weeks' gestation. Ultrasound Obstet Gynecol 2008; 31: 503-6.

11. Gürses C. How to get ductus venosus flow velocity waveforms between 11 and 14 weeks: Candle Flame and Falling Drop Signs. Med Ultrason 2016; 18: 528-9. 
12. Bhide A, Acharya G, Bilardo CM, Brezinka C, Cafici D, HernandezAndrade E, et al. ISUOG practice guidelines: use of Doppler ultrasonography in obstetrics. Ultrasound Obstet Gynecol 2013; 41: 233-9.

13. Martins WP, Kiserud T. How to record ductus venosus blood velocity in the second half of pregnancy. Ultrasound Obstet Gynecol 2013; 42: 245-6.

14. Kiserud T, Eik-Nes SH, Blaas HG, Hellevik LR. Ultrasonographic velocimetry of the fetal ductus venosus. Lancet 1991; 338: 1412-4.

15. Turan OM, Turan S, Sanapo L, Rosenbloom JI, Baschat AA. Semiquantitative classification of ductus venosus blood flow patterns. Ultrasound Obstet Gynecol 2014; 43: 508-14.

16. Torp-Pedersen ST, Terslev L. Settings and artefacts relevant in colour/power Doppler ultrasound in rheumatology. Ann Rheum Dis 2008; 67: 143-9.

17. Hidaka N, Chiba Y. Three-dimensional ultrasonic angiography of fetal, umbilical and placental vasculature using advanced dynamic flow. J Med Ultrasound 2005; 13: 74-8.

18. Kiserud T. The ductus venosus. Semin Perinatol 2001; 25: 11-20.

19. Baschat AA. Examination of the fetal cardiovascular system. Semin Fetal Neonatal Med 2011; 16: 2-12.
20. Mavrides E, Moscoso G, Carvalho JS, Campbell S, Thilaganathan B. The anatomy of the umbilical portal and hepatic venous systems in the human fetus at 14 to 19 weeks of gestation. Ultrasound Obstet Gynecol 2001; 18: 598-604.

21. Yagel S, Kivilevitch Z, Cohen SM, Valsky DV, Messing B, Shen O, et al. The fetal venous system, part I: normal embryology, anatomy, hemodynamics, ultrasound evaluation and Doppler investigation. Ultrasound Obstet Gynecol 2010; 35: 741-50.

22. Kiserud T, Acharya G. The fetal circulation. Prenat Diagn 2004; 24: 1049-59.

23. Mavrides E, Moscoso G, Carvalho JS, Campbell S, Thilaganathan B. The human ductus venosus between 13 and 17 weeks of gestation: histological and morphometric studies. Ultrasound Obstet Gynecol 2002; 19: 39-46.

24. Kiserud T. Re: umbilical vein flow and perinatal outcome in term small-for-gestational-age fetuses. M. Parra-Saavedra, F. Crovetto, S. Triunfo, S. Savchev, G. Parra, M. Sanz, E. Gratacos and F. Figueras. Ultrasound Obstet Gynecol 2013; 42: 189-95.

25. Kessler J, Rasmussen S, Hanson M, Kiserud T. Longitudinal reference ranges for ductus venosus flow velocities and waveform indices. Ultrasound Obstet Gynecol 2006; 28: 890-8. 